\title{
Erratum to: Genome-wide analysis of DNA methylation in an APP/PS1 mouse model of Alzheimer's disease
}

\author{
Lin Cong $\cdot$ Jianping Jia $\cdot$ Wei Qin · \\ Yan Ren $\cdot$ Yongxin Sun
}

Published online: 7 March 2014

(C) Belgian Neurological Society 2014

\section{Erratum to: Acta Neurol Belg \\ DOI 10.1007/s13760-013-0267-6}

The correct order of the authors affiliations is given below.

The Acknowledgment section should read:

Acknowledgments This study was partially supported by the National Key Department of Neurology funded by Chinese Health and Family Planning Committee, the National Natural Science Foundation of China (30600656), the key project of Science and Technology Plan of Beijing Municipal Education Commission (KZ200910025005), Beijing Outstanding Talents Cultivation Fund (2012D005018000007), the High-Level Health Techonology Talent Construction Programme of Beijing Municiple Health Bureau 2013.

The online version of the original article can be found under doi:10.1007/s13760-013-0267-6.

L. Cong

Department of Neurology, Shengjing Hospital of China Medical

University, Shenyang 110817, People's Republic of China

L. Cong · Y. Ren $(\bowtie)$

Department of Neurology, First Affiliated Hospital, China

Medical University, Heping District, Shenyang,

People's Republic of China

e-mail: zhaoyy@sj-hospital.org

L. Cong · J. Jia · W. Qin · Y. Sun $(\bowtie)$

Department of Neurology, Xuanwu Hospital, Capital Medical

University, Beijing 100053, People's Republic of China

e-mail: sisisun@sina.com 